\title{
Revisitando uma biografia: um bate - papo com Fidel Castro
}

\author{
Uelma Alves da Silva ${ }^{1}$
}

RAMONET, Ignacio. Fidel Castro: biografia a duas vozes. São Paulo: Boitempo, 2016. 620p.

\section{Resenha recebida em: 19/01/2020 \\ Resenha publicada em: 05/06/2020}

O livro escrito por Ignacio Ramonet é intitulado Fidel Castro: biografia a duas vozes e foi publicado em 2016 pela editora Boitempo. A obra é uma versão atualizada da primeira edição, publicada em 2006, e aborda a trajetória de Fidel Castro, que concretizou uma revolução em Cuba em 1959. O trabalho é fruto de 300 horas de entrevistas realizadas por Ramonet, que construiu uma destacada carreira como jornalista dirigindo o jornal Le Monde Diplomatique. As entrevistas foram realizadas entre 2003 e 2005, uma obra que, como o próprio autor nomeia, é uma espécie de "livro-conversa".

Não são poucas as biografias de Fidel Castro, afinal esse foi o homem que comandou uma revolução na América Latina em meio à Guerra Fria e teve sempre como obstáculo os Estados Unidos, o país mais desenvolvido economicamente no continente americano. O livro de Ramonet se destaca pela casualidade de uma conversa, o que faz muitas vezes a leitora e o leitor estabelecer um grau de proximidade com os interlocutores, desejando que o entrevistador aprofunde algum tema, ou mesmo querendo fazer muitas perguntas sobre os diversos assuntos que são abordados no livro.

A obra conta com 26 capítulos e aqui apresento um breve resumo de cada um para que a leitora e o leitor percebam a qualidade da obra. O capítulo I - Antecedentes da revolução - é o início desse diálogo e discorre sobre a história de Cuba até os primeiros acontecimentos da Revolução Cubana. No capítulo II - A infância de um líder - Castro relata importantes

\footnotetext{
${ }^{1}$ Mestre em História Política pela Universidade de Brasília (PPG-HIS). Dissertação intitulada: Reflexiones de Fidel: a legitimação da Revolução Cubana durante a normalização das relações Cuba - Estados Unidos sob o governo de Raúl Castro (2009-2016). Bolsa Capes. E-mail para contato: uelma.as@gmail.com.
} 
momentos de sua vida, sua infância e as adversidades pelas quais passou, assim como a formação escolar privilegiada em colégios Jesuítas. Ramonet tenta juntar fatos e fatores da vida do jovem cubano com o intuito de construir sua personalidade rebelde, uma tentativa de encontrar na infância registros do que seria o futuro Fidel Castro, assunto que é discutido especificamente no capítulo III - Como se forja um rebelde. No capítulo IV - Entrando na política - discute-se o contexto político qual vivia Cuba enquanto fazia sua faculdade de direito, período responsável pela sua formação revolucionária e marxista-leninista. Não são abordados assuntos pessoais do comandante, além da presença da família na infância, mas seu relacionamento com Raul Castro é mostrado com maior relevância ao longo da obra como no capítulo V - O assalto ao Quartel Moncada -, no qual revela a responsabilidade que sentia por seu irmão.

Apesar de o livro ser organizado de forma contínua quanto aos acontecimentos da vida do cubano, os assuntos se entrelaçam ao longo de toda a obra. O capítulo VI - "A História me absolverá" - discorre sobre a sua prisão após o ataque ao Quartel Moncada e o fato de ter escrito sua própria defesa durante o julgamento no qual emitiu a frase que dá título ao capítulo. No capítulo VII - Che Guevara -, Castro conversa abertamente sobre o fato de Che ter enfrentado alguns atritos por parte de cubanos pela sua nacionalidade argentina, algo que não repercute tanto na história da Revolução Cubana, considerando que sua imagem é um dos símbolos desse processo. Nesse momento, não há perguntas sobre sua passagem no México no que se refere ao financiamento para a compra dos suplementos para dar continuidade à revolução, isto é, as armas e até o barco Granma, um tópico que é discutido em obras sobre a Revolução Cubana e mesmo em biografias sobre Fidel Castro².

O capítulo VIII - Na Sierra Maestra - aborda a chegada de Fidel a esse lugar que marcou todo o desenrolar do processo revolucionário. Aqui é discutido o esforço de Che Guevara que levou a conquistar seu lugar entre os rebeldes. No capítulo IX - Lições de uma guerrilha - são discutidas as táticas de luta usadas pelos grupos mostrando o caminho escolhido

\footnotetext{
2 Como pode ser encontrado nas obras: GOTT, Richard. Cuba: uma nova história. Rio de Janeiro: Jorge Zahar, 2006; SZULC, Tad. Fidel: Um Retrato Crítico. São Paulo: Best Seller, 1987.
} 
para enfrentar a ditadura de Batista e conquistar o poder, um capítulo no qual a leitora e o leitor compreendem as estratégias utilizadas na revolução em suas especificidades.

No capítulo X - Revolução: primeiros passos, primeiros problemas - ao responder a pergunta de Ramonet sobre a discriminação em relação aos homossexuais, este que se tornou um problema durante a revolução, Fidel Castro atribui ao machismo e à cultura da época os principais fatores que levaram a tantos problemas, assumindo sua parcela de culpa nos conflitos que essa população enfrentou durante os anos. Também responde a questões sobre os problemas com os religiosos e acerca do racismo.

O racismo é um problema espinhoso para a sociedade cubana, considerando principalmente que a abolição ocorreu em 1886, representando, portanto, o penúltimo país a abolir a escravidão, ficando atrás apenas do Brasil. Fidel Castro mostra o histórico da situação a partir do qual afirma que uma das primeiras medidas da revolução foi acabar com os lugares onde não se admitia a população negra. Além disso, reconhece que após o triunfo revolucionário, pensava ser necessário apenas conceber uma lei estabelecendo a igualdade para se resolver tal disparidade, mas foi necessário ir além dessa medida. O problema era mais profundo, e décadas depois do início da revolução Fidel Castro revelou que apesar de estar satisfeito com os avanços realizados, ainda havia problemas não solucionados referentes ao racismo na sociedade cubana.

No capítulo XI - Começam as conspirações - são discutidos os julgamentos dos chamados criminosos que faziam parte do governo de Batista. No capítulo XII - Playa Giróndiscute-se o ataque que os EUA armaram na Baía dos porcos, no qual o primeiro perdeu a batalha. Fidel Castro garantiu a Ramonet, que nenhum dos que foram feitos prisioneiros sofreram agressões pelos revolucionários cubanos. No capítulo XIII - A crise de outubro de 1962 - é discutido um dos eventos mais importantes do período da Guerra Fria, mas não há um relato extenso, tratando-se de um breve capítulo com as opiniões do comandante fazendo um balanço do acontecido. No capítulo XIV - A morte de Che Guevara - Fidel Castro discorre sobre o amigo e seus planos de expandir a guerrilha para outros lugares, como foi o caso da 
ajuda de Cuba a alguns países do continente africano, tópico discutido no capítulo XV - Cuba e África -, no qual é revelada uma grande atuação dos revolucionários cubanos nessa região.

O capítulo XVI - As crises migratórias com os Estados Unidos - apresenta o fluxo problemático de cubanos para os EUA, algo que o entrevistado esclarece ser motivado por muitas razões, como a idealização em relação ao país, levando muitos cubanos a irem para os EUA antes de acontecer à revolução, portanto, sempre ocorreu esse fluxo migratório. Após a revolução, ocorreram três grandes processos emigratórios: Camarioca, Porto de Mariel e A Crise dos Balseiros, eventos que Ramonet discute com o entrevistado. Castro relata como a Lei de Ajuste Cubano se tornou um incentivo para a emigração, um direito concedido especialmente a Cuba, ao contrário de outros países do mundo que não os recebe. Opiniões do cubano que levam o leitor a fazer questionamentos sobre tal lei, tornando este um dos melhores capítulos da obra.

O capítulo XVII - O desmoronamento da União Soviética - serve para acabar com qualquer ilusão acerca de uma unicidade entre os regimes adotados por Cuba e a União Soviética. Fidel Castro reconhece a importância da ajuda Soviética, mas pontua as diferenças governamentais entre os dois países, estas que podem ser minimizadas quando não é feita uma análise particular do sistema Socialista aplicado em Cuba e o sistema adotado pela URSS.

No capítulo XVIII - O caso Ochoa e a pena de morte - Castro fala sobre a pena capital, que é, na sua concepção, uma forma de prevenir más ações e dar exemplo para a sociedade, mas argumenta sobre as especificidades da sua aplicação. Destaca-se o trabalho de Ramonet na tentativa de interrogar o entrevistado quanto aos detalhes sobre a temática. No capítulo XIX Cuba e a globalização neoliberal - Ramonet questiona Fidel Castro sobre assuntos que vinham ganhando força no início do século XXI, tais como a globalização, a preocupação com o meio ambiente e as questões envolvendo os países do Oriente Médio.

No capítulo XX - A visita do Presidente Jimmy Carter - é mostrado o respeito que o cubano tinha para com o ex-presidente dos EUA, e inclusive afirma ter solucionado a crise do Porto de Mariel para não prejudicar a presidência de Carter. No capítulo XXI - A prisão de dissidentes em março de 2003 - discutem-se os ataques, prisões e penas que ocorreram 
envolvendo cidadãos de Cuba e dos Estados Unidos. No capítulo XXII - Os sequestros de abril de 2003 -, Ramonet retoma o assunto da pena capital ao questionar Fidel sobre a execução de três cubanos que sequestraram embarcações, ponderando a severidade da pena.

O capítulo XXIII - Cuba e Espanha - é intrigante por se tratar do momento no qual as relações entre os dois países estavam estremecidas devido a declarações polêmicas de ambos os governos. O entrevistador pergunta ao cubano diretamente sobre o rompimento com Felipe González devido ao posicionamento crítico que ele adotou em relação a Cuba. Da mesma forma, mostra-se o capítulo seguinte XXIV - América Latina -, no qual Castro emite sua opinião sobre diversos dirigentes e políticas da região, chamando atenção seu conhecimento sobre a política exterior.

O trabalho de Ramonet se destaca principalmente nos últimos capítulos do livro ao trazer questões que muitos desejariam perguntar a Fidel Castro. No penúltimo capítulo XXV Cuba hoje -, o cubano é questionado sobre assuntos acerca dos quais o governo é constantemente criticado, como a violação dos Direitos Humanos e a falta de informação crítica sobre os acontecimentos da ilha, fazendo parecer que não havia problemas naquela sociedade, como ocorre em qualquer uma. A resposta de Castro está fundamentada na proteção da revolução, pois as críticas internas, se publicadas, facilitariam os ataques ao governo cubano.

O leitor desse livro encontrará um Fidel Castro franco e sem medo de questionamentos. Quando perguntado sobre a admiração que as pessoas sentem por ele, faz questão de dizer que não aprova o culto à personalidade, enfatizando que em Cuba não há por parte do governo oficial esse tipo de culto à imagem e dialoga com Ramonet sobre sua imagem no campo externo. No último capítulo XXVI - E depois de Fidel? -, são feitas as perguntas cruciais para o comandante, que chegou ao século XXI a frente de um governo, o futuro da revolução é questionado pelo entrevistador e nas respostas do cubano se percebe a franqueza de um líder que perpassou décadas em um sistema político e compreendeu não ser possível controlar todos os aspectos do governo e da sociedade.

Sobre o futuro do governo cubano, já em 2005, Castro garantia a sucessão de seu irmão Raul Castro. Aos 79 anos (a última parte da entrevista foi realizada em 2005), Fidel Castro 
admitia ser ele mesmo muito crítico para com a revolução, o primeiro a apontar os erros para que melhorias acontecessem, relatando alguns para Ramonet, como o enriquecimento ilícito dentro do governo. Essas 300 horas foram de um trabalho singular, pois nessa bibliografia, ou nesse "livro conversa", foi possível descobrir um pouco mais do pensamento e da opinião de Fidel Castro sem um pano de fundo que modificasse a sua imagem, fosse para elogios ou críticas.

Ao término da obra, o leitor pode tirar suas conclusões e testar o poder de convencimento de Fidel Castro, que a todo o momento defende a revolução que realizou em Cuba, admitindo não haver arrependimentos sobre o que foi feito, embora confesse que erros foram cometidos ao longo desses anos. A cordialidade é uma marca das perguntas e das respostas, há questões que poderiam ser aprofundadas, mas a leitora e o leitor entenderão que como qualquer conversa, há assuntos que podem interromper ou deixar o diálogo insustentável, é assim que essa obra se constrói. Ramonet deixa as reticências ao longo do livro, fazendo com que o leitor se lembre de que assim como nas conversas cotidianas, às vezes o pensamento flui em direções diferentes ou surge uma nova ideia que faz com que abandonemos uma frase que seria dita. Essas são algumas das características de tal singular obra e espero que o leitor possa apreciá-la. 